\title{
Biological Activity of the Agrobacterium rhizogenes-Derived trolC Gene of Nicotiana tabacum and Its Functional Relation to Other plast Genes
}

\author{
Hanieh Mohajjel-Shoja, ${ }^{1}$ Bernadette Clément, ${ }^{1}$ Jonathan Perot, ${ }^{2}$ Malek Alioua, ${ }^{1}$ and Léon Otten ${ }^{1}$ \\ ${ }^{1}$ Department of Molecular Mechanisms of Phenotypic Plasticity, Institut de Biologie Moléculaire des Plantes, Rue \\ du Général Zimmer 12, 67084 Strasbourg, France, '²épartement Architecture et Réactivité d'ARN, UPR9002, Institut \\ de Biologie Moléculaire et Cellulaire, 15 Rue Descartes, 67084 Strasbourg, France
}

Submitted 23 June 2010. Accepted 8 August 2010.

\begin{abstract}
Agrobacterium rhizogenes induces hairy roots through the activity of three essential T-DNA genes, $\operatorname{rolA}$, rolB, and rolC, whereas the orf 13 gene acts as an accessory root-inducing gene. rolB, rolC, and orf13 belong to the highly diverged plast gene family with remotely related representatives in the endomycorrhizal basidiomycete Laccaria bicolor. Nicotiana glauca and $N$. tabacum contain A. rhizogenes-derived T-DNAs with active plast genes. Here, we report on the properties of a rolC homolog in $N$. tabacum, trolC. Dexamethasone-inducible trolC and A4-rolC genes from $A$. rhizogenes $A 4$ induce comparable, strong growth effects affecting all parts of the plants. Several have not been described earlier and were found to be very similar to the effects of the distantly related plast gene $6 b$. They include leaf chlorosis and starch accumulation, enations, increase of sucrose-dependent leaf disk expansion, growth of isolated roots on low-sucrose media, and stimulation of sucrose uptake by small root fragments. Collectively, our findings indicate that enhancement of sucrose uptake plays an important role in generating the complex $6 b$ and rolC phenotypes and might be an ancestral property of the plast genes.
\end{abstract}

Agrobacterium rhizogenes is well-known for its capacity to induce hairy roots on a large number of plant species. Different strains harbor root-inducing plasmids (pRi) with different T-DNA structures, but all have a conserved central portion carrying the root locus (rol) genes $\operatorname{rol} A$, rolB, and rolC. These three genes are both necessary and sufficient for hairy-root induction, although pRi8196 does not require rolA (Hansen et al. 1991). orf13 and orf14 enhance rolA-, rolB-, and rolC-induced root growth and are considered to be accessory (Aoki and Syono 1999b; Capone et al. 1989; Costantino et al. 1994; Meyer et al. 2000; Spena et al. 1987). rolA, rolB, rolC, and orf13 modify growth when expressed individually, whereas orf14 does not (Lemcke and Schmülling 1998).

Among the A. rhizogenes T-DNA genes, rolB, rolC, orf13, orf14, and the 5' part of orf8 belong to a family of highly diverged genes without detectable DNA similarity but with sta-

Corresponding author: L. Otten; E-mail: leon.otten@ibmp-cnrs.unistra.fr Nucleotide sequence data is available under accession numbers FN667969 and FN667970. tistically significant similarity at the protein level. They have been called plast genes (for phenotypic plasticity) (Levesque et al. 1988); plast-like genes also occur on the T-DNAs of $A$. tumefaciens and $A$. vitis ( $b, c^{\prime}, d, e, 3$ ', 5, $6 a, 6 b, 7, l s o$, and the $5^{\prime}$ part of iaaM; Helfer et al. 2002), but until now, none were reported outside a T-DNA context. The mechanism of action of plast genes remains controversial, especially since the earlier proposed glucosidase activities of $\mathrm{rolB}$ and $\mathrm{rol} C$ have been questioned (Faiss et al. 1996; Meyer et al. 2000; Nilsson and Olsson 1997; Nilsson et al. 1993).

T-DNAs (called cellular [c]T-DNAs) also occur in Nicotiana glauca and N. tabacum and result from ancient transformation events (Aoki 2004; Furner et al. 1986; Intrieri and Buiatti 2001; Meyer et al. 1995; White et al. 1983). The N. glauca cTDNA (Aoki 2004; Aoki et al. 1994; Furner et al. 1986) has been fully sequenced and consists of two inverted, incomplete T-DNA fragments of a pRi1724-like cT-DNA (Fig. 1). NgrolC (Aoki and Syono 1999a; Nagata et al. 1995) and Ngorf13 (Aoki and Syono 1999c) are transcribed and have morphogenetic activity, whereas $\mathrm{NgrolB}$ is mutated. In the case of $N$. $t a-$ bacum, a trolC (Meyer et al. 1995), a complete and a partial torf13 (Fründt et al. 1998) and a torf14 (Intrieri and Buiatti 2001) sequence have been reported. Mikimopine synthase (mis)like sequences were identified by Southern analysis (Suzuki et al. 2002). The torf13 gene of cultivar Havana 425 induces callus on carrot disks (Fründt et al. 1998), but the activity of trolC has not been tested. Here, we show that N. tabacum cv. Samsun nn has a mutated torfl3 gene and contains only one intact rol gene, trolC. Its growth-modifying properties are very similar to those of the $A$. rhizogenes A4-rolC gene and partially similar to those of the distantly related $6 b$ plast gene, suggesting conservation of an ancestral function.

\section{RESULTS}

N. tabacum cT-DNA contains the three essential rol genes.

Since the publication of the tobacco trolC, torf13, and torf 14 sequences, a large number of tobacco expressed sequence tags (EST) and genomic survey sequences (GSS) have been reported. Among these, we found three torf 8 and two trolB fragments (Table 1). The new tobacco sequences and the $N$. glauca cT-DNA were used to design primers allowing polymerase chain reaction (PCR) amplification of two cT-DNA fragments from $N$. tabacum cv. Samsun nn. The first fragment carries torf8, trolA, trolB, trolC, and torf13, the second torf14 and tmis 
(Fig. 1; accession numbers FN667969 and FN667970, respectively). The two sequences align with the A. rhizogenes TLDNA of pRi1724, but no fragments could be amplified between torf13 and torf14. The torf8-torf13 region is most closely related to sequences from A4 and N. glauca ( 70 and $80 \%$ homology, respectively), whereas torf14-tmis is $96 \%$ homologous to the $N$. glauca sequence up to the right border, but homology does not extend beyond, confirming that torfl4-tmis is not inserted in the same region as Ngorf14-Ngmis in N. glauca, as earlier deduced from Southern analysis (Suzuki et al. 2002). Contrary to $N$. glauca, which lacks rolA, $N$. tabacum contains all three essential $\operatorname{rol}$ genes $(\operatorname{rol} A, \operatorname{rolB}$, and $\operatorname{rol} C)$. However, trolA has an internal stop codon at position 112 (normal open reading frame $[\mathrm{ORF}]=270$ nucleotides $[\mathrm{nt}])$, trolB carries a 40-nt direct repeat (TCAACGCTT-(T/A)-CACCCAAGAAAT CTCACTCGAGCATTGAGC) at position 24 with one mismatch, thereby causing an early frameshift (normal ORF size = $783 \mathrm{nt}$ ), and only trolC is intact. Interestingly, cv. Samsun nn torf13 (S-torf13) differs from cv. Havana 425 torf13-1 ( $\mathrm{H}$ torf13-1) (AJ007621). H-torf13-1 is intact, but $S$-torf13 is truncated beyond nt 400, as shown by PCR experiments with $H$ torf13-1 primers downstream from position 400 (not shown). The torfl3 genes of N. tabacum cv. Wisconsin 38 and N. tomentosiformis are intact, whereas those of $N$. tabacum cv. Basma Drama 2, Samsun, and Xanthi are truncated (results not shown). torf8 has a stop codon at position 1,873 (normal ORF size $=2,286 \mathrm{nt}$ ). torf14 is intact, and tmis has a stop codon at position 199 (normal ORF size $=987 \mathrm{nt}$ ). Thus, trolC is the only potentially growth-modifying cT-DNA gene in cv. Samsun nn. This gene is expressed as shown by reverse transcription quantitative (RT-q)PCR analysis. In medium-sized leaves of $N$. tabacum Samsun nn plants (height $20 \mathrm{~cm}$ ), the trolC/EF2

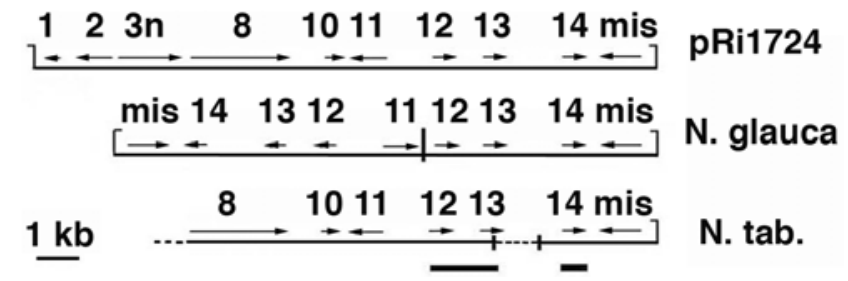

Fig. 1. T-DNA and cellular (c)T-DNA maps. pRi1724: TL-DNA of Agrobacterium rhizogenes 1724 (NC_002575.1). N. glauca: cT-DNA of Nicotiana glauca (Suzuki et al. 2002). N. tabacum: cT-DNA fragments of $N$. tabacum (this work). Arrows: open reading frames. 10, 11 and 12: rolA, rolB, and rolC. mis: mikimopine synthase gene. Thick horizontal lines: earlier published sequences from $N$. tabacum. expression ratio (tested with appropriate primers as discussed below) is $1.0 \times 10^{-4}$ (standard deviation $\left.=0.3 \times 10^{-4}\right)$.

\section{Inducible expression of dex-trolC-HAHIS and dex-A4-rolC-HAHIS in tobacco.}

Earlier studies showed that trolC is transcribed (Meyer et al. 1995), but its biological activity has not been investigated. The A. rhizogenes A4-rolC gene causes dwarfing in tobacco and pale-green lanceolated leaves (Schmülling et al. 1988). Therefore, we used A4-rolC as a standard to test trolC. In order to detect the proteins, we added an HAHIS tag (Thomas et al. 2006) at the $3^{\prime}$ end of both genes. Experiments in our laboratory with other inducible HAHIS constructs showed that this construct does not modify tobacco growth, even at high expression levels, as detected with the anti-HAHIS antibody (results not shown). We therefore felt confident that this tag would not disturb plant growth. The tagged constructs were placed under inducible promoter control using the pTA7002 vector (Aoyama and Chua 1997), as earlier done for the $T-6 b$ plast gene (Grémillon et al. 2004). The pTA7002 vector allows controlled gene induction by addition of dexamethasone (dex) to the medium or by spraying plants with a dex solution. $N$. $t a-$ bacum plants carrying a dex-GFP gene in the same pTA7002 vector (Shen 2001) and induced to high GFP levels did not show any particular growth effects under the conditions used in this work (results not shown). Dex-inducible dex-trolC$H A H I S$ and dex-A4-rolC-HAHIS genes were introduced in $N$. tabacum cv. Samsun nn (discussed below). Several independent transgenic lines showed high levels of tRolC-HAHIS or A4-RolC-HAHIS protein $24 \mathrm{~h}$ after leaf infiltration with dex. Five homozygous single-locus F2 lines (dex-trolC-HAHIS-7, dex-trolC-HAHIS-13, and dex-A4-rolC-HAHIS-6, dex-A4rolC-HAHIS-7, and dex-A4-rolC-HAHIS-10) with high expression levels (Fig. 2A) were chosen for further studies. When seedlings of these lines were grown on inducing medium with $3 \mu \mathrm{M}$ dex, they showed a comparable growth reduction, reproducing the earlier reported rolC dwarfing phenotype (Fig. 2B). The dex-trolC-HAHIS-7 and dex-A4-rolC-HAHIS-7 lines were selected for further detailed studies. The phenotypic range for trolC and A4-rolC was determined with different inducer concentrations. Seedlings were grown on nylon filters on vertical plates containing media with dex concentrations ranging from 0 to $3 \mu \mathrm{M}$. Results are shown in Figure 3. tRolCHAHIS and A4-RolC-HAHIS proteins reached maximal levels at $0.3 \mu \mathrm{M}$ dex (Fig. 3A). At more than $0.03 \mu \mathrm{M}$ dex, cotyledons and leaves were smaller and pale green (Fig. 3B). Root hairs of dex-trolC-HAHIS-7 and dex-A4-rolC-HAHIS-7 seed-

Table 1. Overview of Nicotiana tabacum cellular (c)T-DNA sequences

\begin{tabular}{lllll}
\hline cT-DNA region & Tobacco cultivar & \multicolumn{1}{c}{ Accession no. } & \multicolumn{1}{c}{ Reference } & DNA type \\
\hline torf8 & Petit Havana & EH664027 & Millar et al., ${ }^{\text {a } \text { unpublished }}$ & c-DNA \\
torf8 & Hicks Broadleaf & FH900730 & Opperman et al., ${ }^{\mathrm{b}}$ unpublished & Genomic DNA \\
torf8 & Hicks Broadleaf & FH901074 & Opperman et al., unpublished & Genomic DNA \\
torf8 & Samsun nn & FN667969 & This paper & Polymerase chain reaction (PCR) \\
trolA & Samsun nn & FN667969 & This paper & PCR \\
trolB & Petit Havana & EH664294 & Millar et al., unpublished & c-DNA \\
trolB & Hicks Broadleaf & FH925392 & Opperman et al., unpublished & Genomic DNA \\
trolB & Samsun nn & FN667969 & This paper & PCR \\
trolC & Havana 425 & X91881 & Meyer et al. 1995 & PCR \\
trolC & Samsun nn & FN667969 & This paper & PCR \\
trolC-torf13 & Havana 425 & AJ010794, AJ007621, AJ007622 & Fründt et al. 1998 & PCR \\
torf13 & Not specified & AF281242 & Intrieri and Buiatti 2001 & PCR \\
torf13 & Samsun nn & FN667969 & This paper & PCR \\
torf14 & Not specified & AF281246 & Intrieri and Buiatti 2001 & PCR \\
torf14 & Samsun nn & FN667970 & This paper & PCR \\
tmis & Samsun nn & FN667970 & This paper & PCR \\
\hline
\end{tabular}

${ }^{\mathrm{a}}$ D. J. Millar, L. V. Bindschedler, and G.P. Bolwell.

${ }^{b}$ C. Opperman, S. Lommel, and M. Burke. 
lings became shorter at $0.01 \mu \mathrm{M}$ dex and disappeared at 0.3 $\mu \mathrm{M}$ (Fig. 3C), and root growth slowed down (Fig. 3D) from $0.1 \mu \mathrm{M}$ dex onwards. At later stages, cotyledons and first true leaves became chlorotic, thick, and epinastic. However, subsequent leaves and lateral roots of dex-trolC-HAHIS-7 seedlings normalized contrary to those of dex-A4-rolC-HAHIS-7 seedlings (Fig. 3E and F, also discussed below).

In order to compare trolC and A4-rolC effects on plants growing under greenhouse conditions, dex-trolC-HAHIS-7, and dex-A4-rolC-HAHIS-7 seeds were germinated in soil and were sprayed with $3 \mu \mathrm{M}$ dex at the two-cotyledon stage. Dexsprayed trolC and $A 4$-rolC plants showed considerable growth reduction compared with wild-type plants (Fig. 4A). At later stages, side shoots replaced the main shoots, which appeared to be blocked. Surprisingly, several plants showed enations along the central leaf veins (Fig. 4B). Enations are a rare type of plant growth modification found in some viral diseases and in tobacco plants that express $2 \times 35 S-A B-6 b$ (Helfer et al. 2003) or dex-T-6b (Grémillon et al. 2004) constructs derived from two $6 b$ genes from the $A$. vitis nopaline strain $\mathrm{AB} 4$ and the $A$. vitis octopine and cucumopine strain Tm4, respectively. The induction of enations reveals an unsuspected, highly specific

A

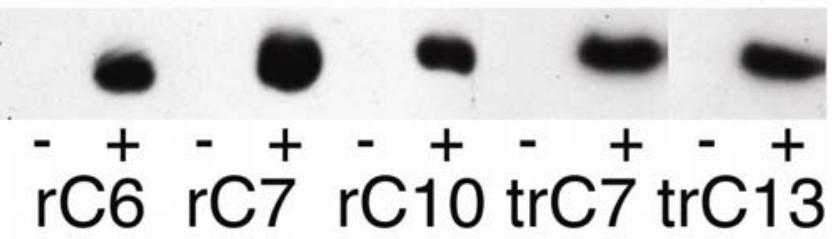

$\mathrm{B}$

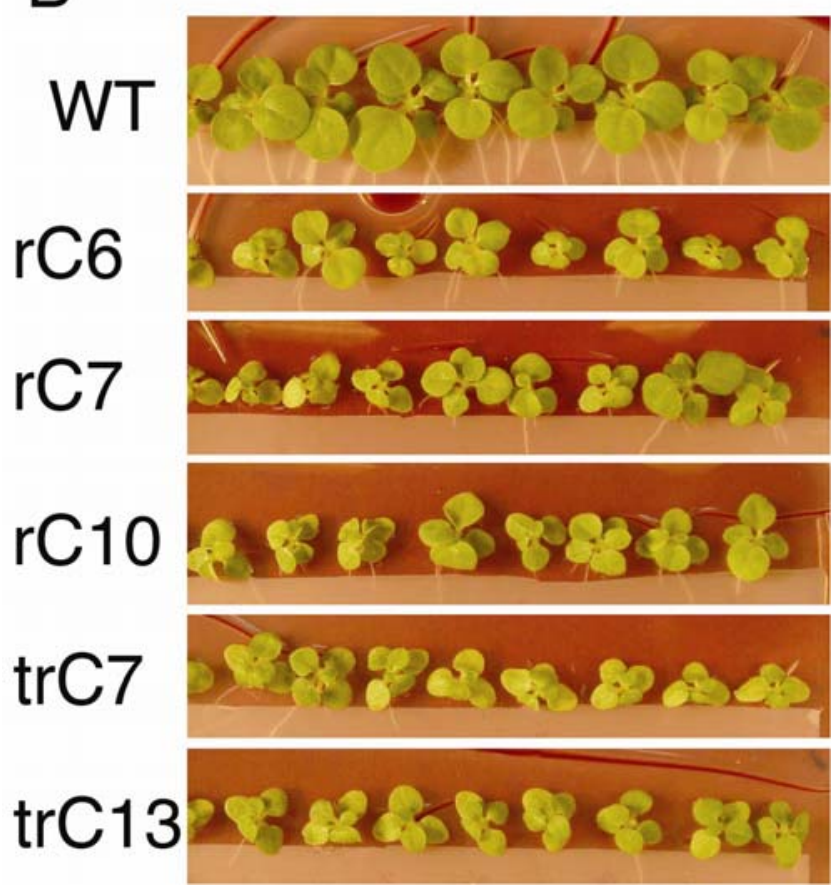

Fig. 2. Initial characterization of transformed homozygous lines. A, Expression of transgene-encoded proteins $24 \mathrm{~h}$ after leaf infiltration with 10 $\mathrm{mM} \mathrm{MgSO}_{4}(-)$ or with $3 \mu \mathrm{M}$ dexamethasone (dex) in $10 \mathrm{mM} \mathrm{MgSO}_{4}(+)$. Each sample contains the same total amount of protein. B, Phenotypes of induced seedlings 8 days after transfer to medium with $3 \mu \mathrm{M}$ dex. Growth of induced trolC and A4-rolC lines has slowed down. WT $=$ rC6, rC7, rC10, trC7 and trC13; wild-type = dex-A4-rolC-HAHIS-6, dex-A4-rolCHAHIS-7, dex-A4-rolC-HAHIS-10, dex-trolC-HAHIS-7, and dex-trolCHAHIS-13, respectively. relation between rolC and $6 b$ plast genes. When dex-trolCHAHIS-7 and dex-A4-rolC-HAHIS-7 plants at a height of 20 $\mathrm{cm}$ were sprayed with $3 \mu \mathrm{M}$ dex, narrow leaves with irregular chlorosis patterns developed (Fig. 4C), demonstrating that trolC and A4-rolC not only interfere with early development but also induce changes in older plants. Chlorosis could be

\section{dex-A4-roIC-HAHIS dex-troIC-HAHIS}
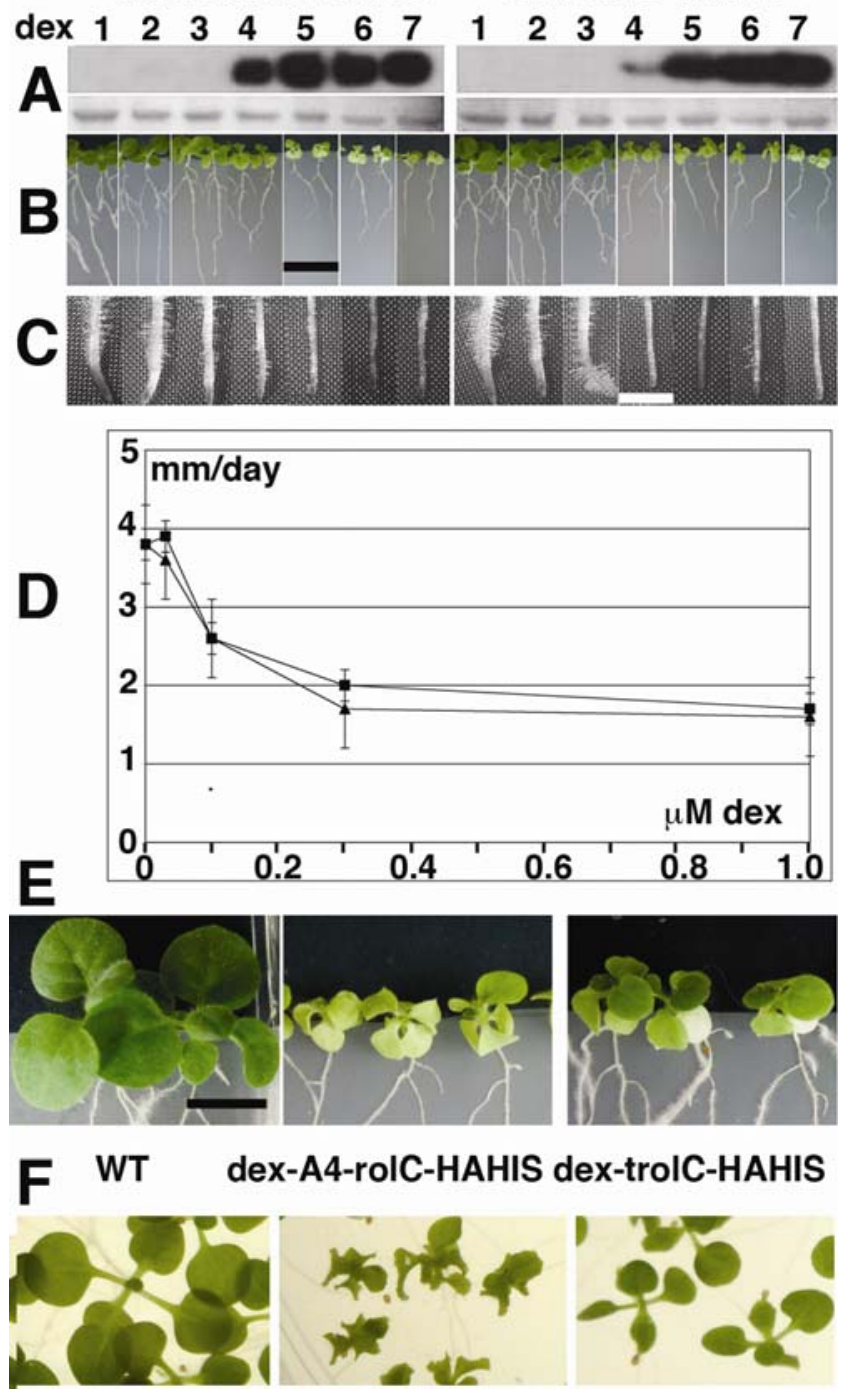

Fig. 3. Control of dex-A4-rolC-HAHIS and dex-trolC-HAHIS expression by different dex (dexamethasone) concentrations and associated phenotypes. Dex-A4-rolC-HAHIS-7 and dex-trolC-HAHIS-7 seedlings were induced on media with $0,0.01,0.03,0.1,0.3,1$, and $3 \mu \mathrm{M}$ dex (lanes 1 to 7 , respectively). A, Western analysis of A4-RolC-HAHIS and tRolC-HAHIS proteins with an antihemagglutinin antibody, $24 \mathrm{~h}$ after induction. Top: A4-RolC-HAHIS and tRolC-HAHIS proteins. Bottom: loading control. A4-RolC and tRolC proteins are detectable from $0.1 \mu \mathrm{M}$ dex onwards. B, Seedlings 8 days after induction. Shoots are chlorotic and smaller from 0.1 $\mu \mathrm{M}$ dex onwards. Bar $=2 \mathrm{~cm}$. C, Roots 8 days after induction. Root hairs are reduced from $0.03 \mu \mathrm{M}$ dex onwards. Bar $=0.25 \mathrm{~cm}$. D, Root growth (mm/day) of seedlings decreases with increasing dex concentration. Squares = dex-trolC-HAHIS-7, triangles = dex-A4-rolC-HAHIS-7. Values are means \pm standard deviation. For each timepoint, 24 seedlings were measured. Experiments were repeated three times. Experimental errors were less than 3\%. E, Wild type, dex-A4-rolC-HAHIS-7, and dex-trolCHAHIS-7 seedlings 18 days after induction. Dex-A4-rolC-HAHIS-7 seedlings remain highly abnormal and yellow but dex-trolC-HAHIS-7 seedlings normalize, i.e., new leaves are normal and dark green and new lateral roots have normal root hairs. Bar $=1 \mathrm{~cm}$. F, Wild type, dex-A4-rolC-HAHIS-7, and dex-trolC-HAHIS-7 seedlings 28 days after induction. Dex-A4rolC-HAHIS-7 seedlings continue to generate abnormal leaves, whereas dex-trolC-HAHIS-7 seedlings produce normal leaves. $\mathrm{Bar}=1 \mathrm{~cm}$. 

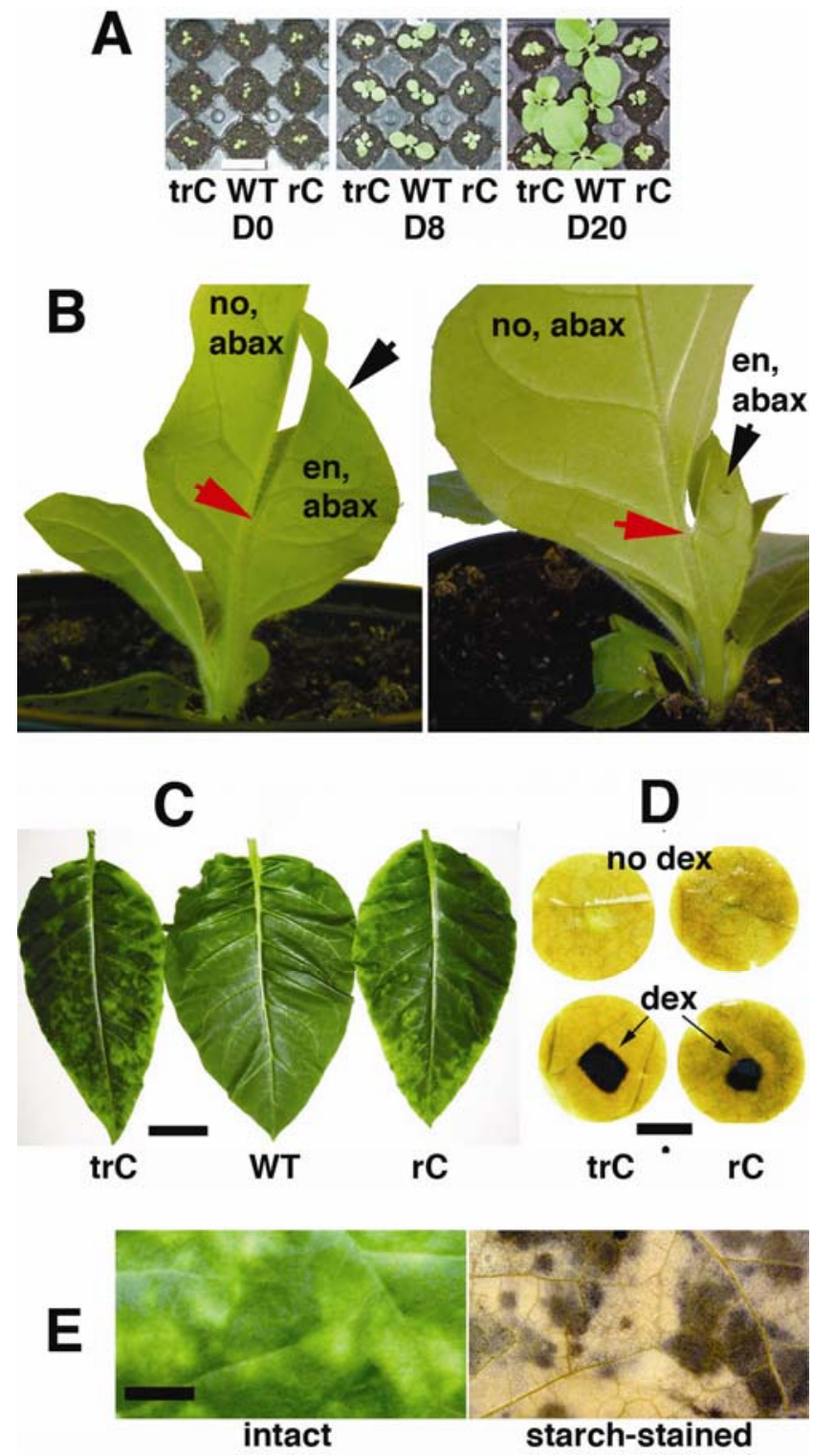

Fig. 4. trolC and A4-rolC modify growth of tobacco plants in soil. Wild type (WT), dexamethasone (dex)-trolC-HAHIS-7 (trC), and dex-A4rolC-HAHIS-7 (rC) plants were sprayed with $3 \mu \mathrm{M}$ dex solution. A, Seedlings after induction at the 2-cotyledon stage on day 0, 8 and 20 . Wild-type plants develop normally, dex-A4-rolC-HAHIS-7 and dextrolC-HAHIS-7 plants show reduced growth. Bar $=3 \mathrm{~cm}$. B, Enations (black arrows) on dex-trolC-HAHIS-7 (trC, on the left) and dex-A4rolC-HAHIS-7 ( $\mathrm{rC}$, on the right) plants 40 days after induction at the two-cotyledon stage. no, abax = normal leaf, abaxial side. en, abax = enation, abaxial side. Enations are abnormal, extra leaf blades that are partially fused at their basal side to a normal leaf along the central leaf veins and are oriented in a mirror-wise fashion. Red arrows point to locations on the midveins where normal leaves and enations separate. $\mathbf{C}$, Leaves of plants induced at an intermediate, nonflowering stage, 7 days after induction. Dex-trolC-HAHIS-7 (trC) and dex-A4-rolC-HAHIS-7 (rC) leaves show irregular chlorosis patterns and are reduced in width compared with a wild-type leaf $(\mathrm{WT})$. Bar $=2 \mathrm{~cm}$. D, Iodine staining revealing starch (black areas) in dex-trolC-HAHIS-7 (trC) and dex-A4rolC-HAHIS-7 (rC) leaves, 7 days after local induction with a dex-containing lanolin sphere placed at the center. Upper two disks were treated with lanolin spheres without dex; lower two disks were treated with lanolin spheres with $10 \mu \mathrm{M}$ dex. Starch accumulates within a small zone around the inducing lanolin sphere. Bar $=1 \mathrm{~cm}$; the small black dot shows size of the lanolin sphere. E, Starch accumulation in a dexsprayed dex-A4-rolC-HAHIS-7 leaf. Left: Irregular chlorosis as in C. Right: Same area cleared with hot $70 \%$ ethanol and stained with iodine for starch; starch appears black. Chlorotic and starch-containing areas coincide. induced locally by placing small lanolin spheres containing 10 $\mu \mathrm{M}$ dex on well developed leaves; the induced areas not only became chlorotic but also accumulated high levels of starch, as revealed by iodine staining (Fig. 4D), showing that trolC and A4-rolC can act directly on mature leaf tissues. The chlorotic areas of uniformly sprayed leaves also correspond to high starch zones (Fig. 4E). Starch accumulation has also been reported for $6 b$ (Clément et al. 2006; Helfer et al. 2003) and for the rolB-like 5 ' part of orf8 (Umber et al. 2002). The local induction of starch accumulation by lanolin spheres might suggest that trolC and A4-rolC directly affect leaf-specific processes (like photosynthesis). The root changes observed in seedlings could then be an indirect result of these leaf changes. Alternatively, trolC and A4rolC act on processes that are found in both leaves and roots, which would indicate a more general cellular target. As a next step, we therefore tested the effects of trolC and A4-rolC on isolated shoots and roots by using leaf disks and isolated roots.

\section{trolC and $A 4-r o l C$ induce changes in leaf disks.}

Induction of dex-trolC-HAHIS and dex-A4-rolC-HAHIS seedlings strongly reduces shoot and root growth. When roots were removed before induction, isolated induced shoots still slowed down their growth and became chlorotic, confirming that the action of trolC and A4-rolC on leaves is direct and does not require previous modification of roots. Local starch accumulation in leaves is most likely due to sucrose accumulation, which was analyzed using a sucrose-dependent leaf-disk expansion assay. Tobacco leaf disks from immature leaves floated on a simple medium (Keller and Van Volkenburgh 1997) will expand to a limited extent on medium without sucrose. When 3\% sucrose is added, expansion increases by about $60 \%$. The expansion of dex-trolC-HAHIS-7 and dex-A4-rolCHAHIS-7 leaf disks in 3\% sucrose was further increased upon induction with dex, whereas no increase occurred when the inducing medium contained no sucrose (Fig. 5). It can therefore be hypothesized that $A 4$-rolC and trolC stimulate the uptake of sucrose from the medium, which then leads to increased

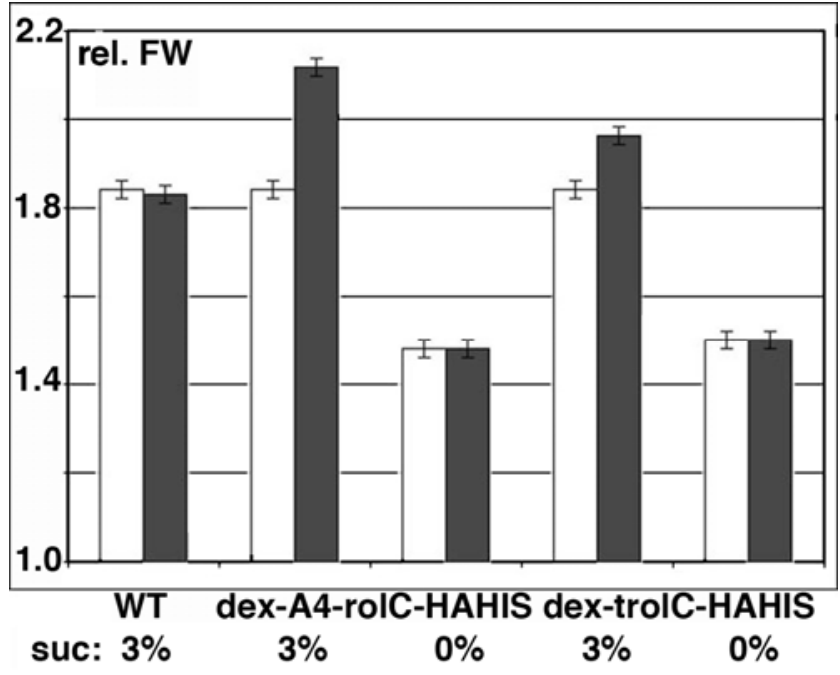

Fig. 5. Increase of leaf disk expansion by trolC and A4-rolC and dependence on sucrose. Disks of wild-type, dexamethasone (dex)-A4-rolCHAHIS-7 and dex-trolC-HAHIS-7 lines were placed on liquid medium, and expansion after 5 days was expressed as the ratio of fresh weight at day 5 over the fresh weight at day 0 , indicated as relative fresh weight. White bars $=$ no induction, black bars $=$ induction by $3 \mu \mathrm{M}$ dex. Induced dex-A4-rolC-HAHIS and dex-trolC-HAHIS disks show increased expansion but only on sucrose-containing media. Values are means \pm standard deviation. For each medium, 12 disks were measured per line. Experiments were repeated twice. Experimental errors were less than $1 \%$. 
expansion. Since $T-6 b$ also stimulates tobacco-leaf disk expansion in the presence of sucrose (Clément et al. 2006), this further confirms the functional relation between rolC and $6 b$ (discussed above).

trolC and $A 4-r o l C$ induce changes in isolated roots.

Isolated tobacco roots do not grow on medium with $1 \%$ sucrose. However, on the same medium, isolated dex-induced trolC and A4-rolC roots continued to grow, although they lost their root hairs, as in the case of intact seedlings. Sensitivity to sucrose was tested by placing dex-trolC-HAHIS-7 and dexA4-rolC-HAHIS-7 roots on media with different sucrose concentrations (from 0 to $2 \%$ ) with or without $3 \mu \mathrm{M}$ dex. Growth did not occur on medium without sucrose but was already visible at $0.1 \%$; both lines showed similar sensitivity (Fig. 6A). Interestingly, dex-trolC-HAHIS-7 roots grew, initially, as fast as dex-A4-rolC-HAHIS-7 roots but ceased growth at day 5, whereas dex-A4-rolC-HAHIS-7 roots continued their growth for more than 10 days, an example ( $3 \mu \mathrm{M}$ dex and $1 \%$ sucrose) is shown in Figure 6B. Growth of isolated roots on low sucrose has also been demonstrated for dex-T-6b roots, and absorption of radioactively marked sucrose by these roots increased significantly upon induction (Clément et al. 2007). Sucrose uptake by dex-trolC-HAHIS-7 and dex-A4-rolC-HAHIS-7 root
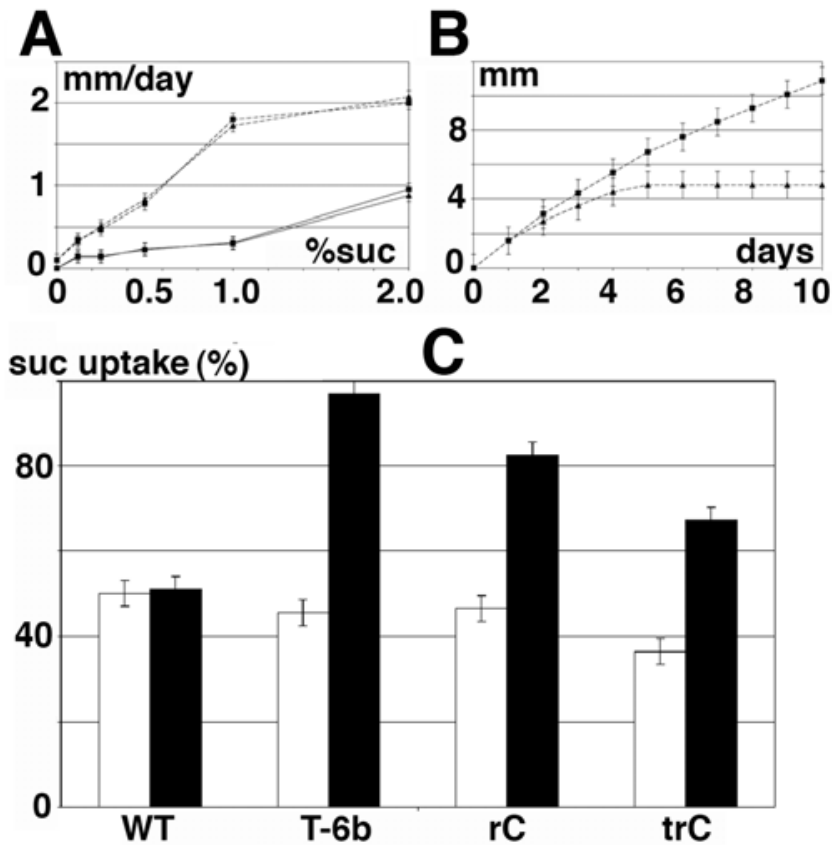

Fig. 6. Influence of rolC and trolC on root growth and sucrose uptake. A, Growth of dexamethasone (dex)-A4-rolC-HAHIS-7 (squares) and dex-trolCHAHIS-7 roots (triangles) grown on different sucrose concentrations, shown in $\mathrm{mm} /$ day over a 5 -day period. Continuous lines $=$ noninducing medium, broken lines $=$ inducing medium. $\mathbf{B}$, Length increase (in $\mathrm{mm}$ ) of dex-A4rolC-HAHIS-7 (squares) and dex-trolC-HAHIS-7 roots (triangles) on medium with $1 \%$ sucrose and $3 \mu \mathrm{M}$ dex, during a 10 -day induction period. DexA4-rolC-HAHIS-7 roots show regular growth; growth in dex-trolC-HAHIS7 roots slows down and stops at day 5. For A and B, values are means \pm standard deviation. For each condition, 10 roots were measured per line. Experiments were repeated three times. Experimental errors were less than 3\%. C, Sucrose uptake by subapical 3-mm-long root fragments of wild-type (WT), dex-T-6b (T-6b), dex-A4-rolC-HAHIS-7 (rC), and dex-trolC-HAHIS-7 (trC) lines, without induction (white bars) or after induction with $3 \mu \mathrm{M}$ dex (black bars). Dex-T-6b, dex-A4-rolC-HAHIS-7, and dex-trolC-HAHIS-7 lines show a clear increase in sucrose uptake, while the WT control does not. Data are expressed as percentage of sucrose taken up after $24 \mathrm{~h}$. Values are means \pm standard error. Root fragments were pooled in groups of five; ten groups were used per line. Experiments were repeated two times. Experimental errors were less than $10 \%$. fragments was measured in the same way, using wild-type tobacco and the dex-T-6b line D6Nt17 (Clément et al. 2007) as negative and positive controls, respectively. Sucrose uptake of wild-type tobacco-root fragments was not modified by dex treatment, whereas root fragments of induced dex-T-6b, dextrolC-HAHIS-7, and dex-A4-rolC-HAHIS-7 seedlings showed a clear increase in sucrose uptake (Fig. 6C).

Expression of dex-trolC-HAHIS is affected by silencing.

In the course of our induction studies, some dex-trolC$H A H I S$-induced growth changes rapidly reversed to normal in spite of the continued presence of inducer; shoots and lateral roots normalized (Fig. $3 \mathrm{E}$ and $\mathrm{F}$ ), whereas isolated roots stopped their growth on $1 \%$ sucrose (Fig. 6B). Dex-A4-rolCHAHIS changes, on the contrary, appeared stable. This difference in phenotype stability might be due to differences in tRolC and A4-RolC protein stability. Protein levels were compared for different induction times. Whereas A4-RolC-HAHIS protein levels remained stable for 2 weeks, tRolC-HAHIS protein showed a decrease starting after day 1 , resulting in very low levels after 2 weeks (Fig. 7A). Transgene transcripts measured by RT-qPCR were found to decrease in dex-trolC-HAHIS-7 and dex-A4-rolC-HAHIS-7 seedlings, but more rapidly and to lower levels in dex-trolC-HAHIS-7 (Fig. 7B). Dex-trolCHAHIS-7 plants showed increasing amounts of a 21-nt siRNA, demonstrating post-transcriptional gene silencing; dex-A4rolC-HAHIS-7 plants did not (Fig. 7C).

\section{Expression of trolC and A4-rolC in Arabidopsis thaliana.}

Our results show that dex-trolC-HAHIS expression is rapidly silenced in tobacco. Expression of exogenous trolC and A4rolC genes in tobacco might therefore lead to silencing of the endogenous tobacco trolC gene and make it difficult to distinguish between the effects of exogenous and endogenous rolC genes. In order to confirm trolC activity in a plant species lacking rolC-like genes, we transformed Arabidopsis thaliana

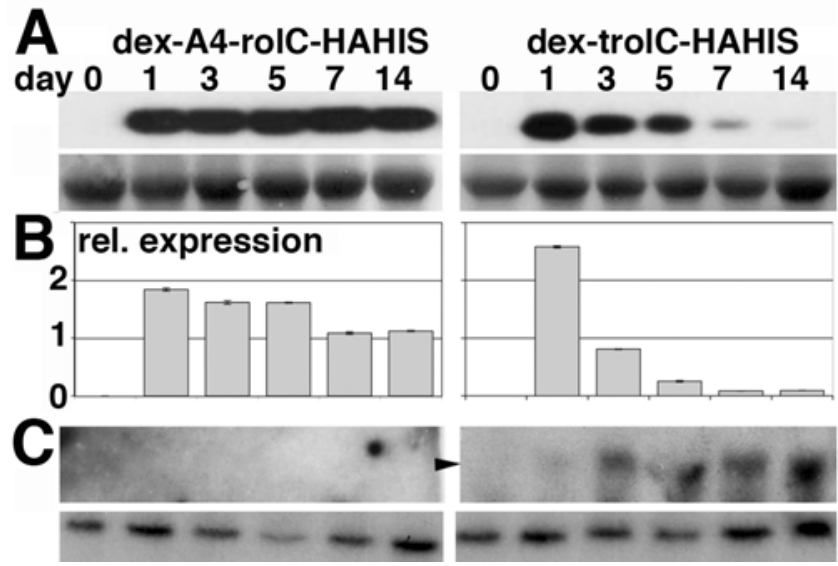

Fig. 7. Progressive silencing of dexamethasone (dex)-A4-rolC-HAHIS-7 and dex-trolC-HAHIS-7 after induction. Seedlings were placed on medium with $3 \mu \mathrm{M}$ dex and were analyzed $0,1,3,5,7$, and 14 days later. $\mathbf{A}$, Western analysis. Top, A4-RolC-HAHIS and tRolC-HAHIS proteins. Bottom, loading control. Whereas A4-RolC-HAHIS amounts remain stable, tRolC-HAHIS levels rapidly decline. B, Reverse transcription quantitative polymerase chain reaction (RT-qPCR) analysis. The same samples shown in A were analyzed for mRNA levels by RT-qPCR. Units = relative expression levels $\times 0.0001$ (calculated with respect to values at day 0 , set at 1 ). Dex-A4-rolC-HAHIS mRNA levels decline slowly, whereas dex-trolCHAHIS mRNA levels decline more rapidly. C, siRNA analysis. Top, dexA4-rolC-HAHIS samples show no signal, whereas dex-trolC-HAHIS samples show increasing quantities of a 21-nucleotide siRNA (arrow). Bottom, RNA loading control obtained by hybridizing the filter to a U6 RNA probe (Gy et al. 2007) 
ecotype Col-0 with $2 \times 35 S$-trolC, $2 \times 35 S$-A4-rolC, $2 \times 35 S$-trolCHAHIS, 2x35S-A4-rolC-HAHIS, and the pBI121.2 vector control. Plants of the T3 generation expressing trolC or A4-rolC (with or without HAHIS tag) showed similar phenotypes. Root growth was strongly reduced (Fig. 8A), flowering occurred early, both in vitro and in vivo (Fig. 8B and C, respectively), and plants were slightly less green than control plants. Thus, trolC and $A 4$-rolC are biologically active in a plant species without an endogenous rolC gene.

\section{Plast-like proteins in another eukaryote, Laccaria bicolor.}

So far, plast genes have only been reported in Agrobacterium species and a few Nicotiana species. In the latter group, they are clearly derived from Agrobacterium species by horizontal transfer. The plast proteins similarly constitute an isolated group of unknown origin (Studholme et al. 2005). However, a recent databank search identified five Laccaria bicolor S238N-H82 proteins with unknown function as possible plastlike proteins: EDR08145.1 (National Center for Biotechnology Information number XP_001881215.1, 491 amino acids [aa], EDR04342.1 (XP_001884861.1, 451 aa), EDR04443.1 (XP_001884962.1, 273 aa), EDR04444.1 (XP_001884963.1, $284 \mathrm{aa}$ ), and EDR04445.1 (XP_001884964.1, 409 aa) (Martin et al. 2008). Four of the five proteins (XP_001884861.1, XP_001884962.1, XP_001884963.1, and XP_001884964.1) are coded by genes clustered within a $33-\mathrm{kb}$ region. The common region of the five Laccaria proteins is about 250 amino acids in size, corresponding to the average size of the Agrobacterium plast proteins (Fig. 9A), and similarity values between the common regions range from 56 to 84\%. XP_001884962.1 aligns with almost all plast proteins above statistically significant levels (not shown), whereas the four others only show significant homology to plast proteins $\mathrm{C}^{\prime}$, D, and 5. Similarity values between plast and Laccaria proteins are in the range of inter-plast similarity values (about 20\%). An alignment of XP_001884962.1 and the Agrobacterium plast protein with the highest similarity score (protein 5) is shown in Figure 9B.

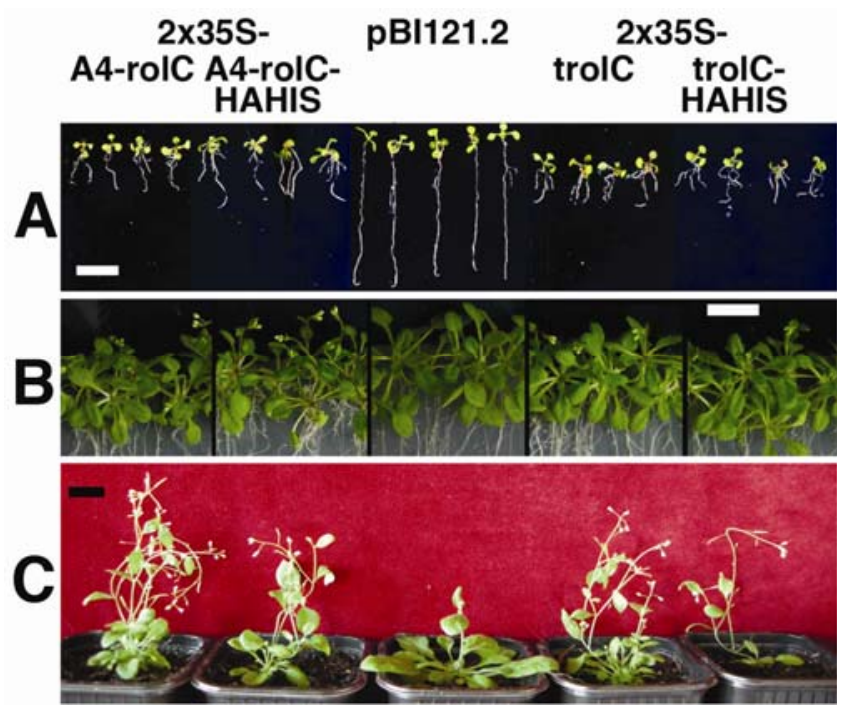

Fig. 8. Expression of A4-rolC and trolC in Arabidopsis thaliana. Tagged and nontagged versions of $A 4$-rolC and trolC under $2 \times 35 S$ promoter control and the empty pBI121.2 vector construct were used to transform Arabidopsis thaliana ecotype Col-0. T3 plants are shown. A, At 10 days after germination in vitro. Both the tagged and nontagged A4-rolC and trolC versions cause strong root growth inhibition, pBI121.2 vector plants are normal. B, At 21 days after germination in vitro. Early flowering of plants with tagged and nontagged versions of A4-rolC and trolC. $\mathbf{C}$, At 32 days after germination in soil. Early flowering of plants with tagged and nontagged versions of $A 4$ rolC and trolC. Bars in $\mathrm{A}$ and $\mathrm{B}=1 \mathrm{~cm}$, in $\mathrm{C}=2 \mathrm{~cm}$.

\section{DISCUSSION}

The Nicotiana cT-DNAs constitute the only known examples of naturally occurring DNA transfer in plants. Among the many unsolved questions regarding this phenomenon are those concerning the relation between the $N$. tabacum and $N$. glauca cT-DNAs, the present-day role of the cT-DNA genes, and the survival of the initial regenerants. The relation between the Nicotiana tabacum cT-DNAs and those of $N$. glauca are more complex than suspected. Two nonadjacent sequences occur in N. tabacum. The first carries torf8 to torf13 (with possibly an extension to the left) and is moderately related (70 to $80 \%$ homology) to the corresponding sequences from $A$. rhizogenes A4 and N. glauca. The second one carries torf14 and tmis and extends up to the right border; this sequence is practically identical (96\% homology) to the N. glauca Ngorf14-Ngmis region but is inserted in a different region. It should be noted that the evolution of Nicotiana species is extremely complex because of the occurrence of interspecific hybrids. Trees for different Nicotiana genes do not always coincide, so that no consensus has yet emerged for trees that reflect the evolution of the entire species (Kelly et al. 2010). Therefore, the tree we present in Figure 10A only reflects the evolution of the cT-DNA regions in the different species and does not pretend to represent species evolution.

To account for the present data, we propose the following evolutionary scenario (Fig. 10A). First, the two arms of the inverted repeat of the cT-DNA of $N$. glauca are clearly derived from a single transformation event (Fig. 10A, arrow 1, the inverted repeat structure is indicated by a) and, therefore, had initially the same sequence. The 5\% divergence between the two arms (Furner et al. 1986) is due to divergent evolution between the two arms. The torf14-tmis sequence of $N$. tabacum shows $4 \%$ divergence with respect to the two Ngorf14-Ngmis sequences but is located in another site. The easiest assumption is that the torf14-tmis fragment (Fig. 10A, fragment b) de-

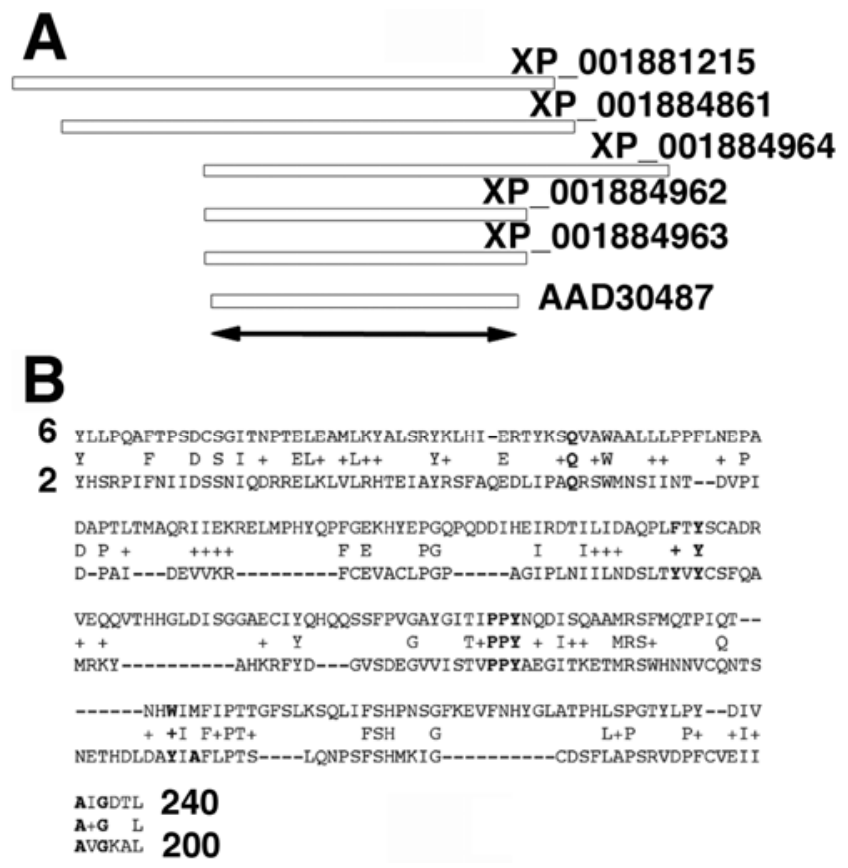

Fig. 9. Plast-like proteins in Laccaria bicolor. A, Schematic alignment of five Laccaria bicolor plast-like proteins with the Agrobacterium plast protein AAD30487 (gene 5 protein from A. tumefaciens C58). Double-headed arrow indicates the common part of plast proteins, about 250 amino acids. B, Alignment of protein XP_001884962.1 from Laccaria bicolor (top line) with gene 5 protein (bottom line). Bold indicates residues conserved in the Agrobacterium plast family. 
rives from the same transformation event and T-DNA as fragment a but was inserted elsewhere. Later, fragment $a$ and $b$ separated and are now found in two different Nicotiana species. Secondly, since trolB-torf13 (Fig. 10A, fragment c) and NgrolBNgorf13 differ by about $20 \%$, we propose that trolB-torf13 (fragment c) originates from another T-DNA than NgrolBNgorf13 and, therefore, from another transformation event (Fig. 10A, arrow 2). The order of entry ( 1 before 2 or 2 before 1 ) is unknown, and both fragments might have been combined by crosses rather than by a secondary transformation. Thirdly, the torf8-torf13 fragment underwent a modification at the torf13 end (Fig. 10A, $\mathrm{c}$ to $\mathrm{c}^{\prime}$, modification indicated by arrow $3)$. The tobacco cultivars with a truncated torf13 gene belong
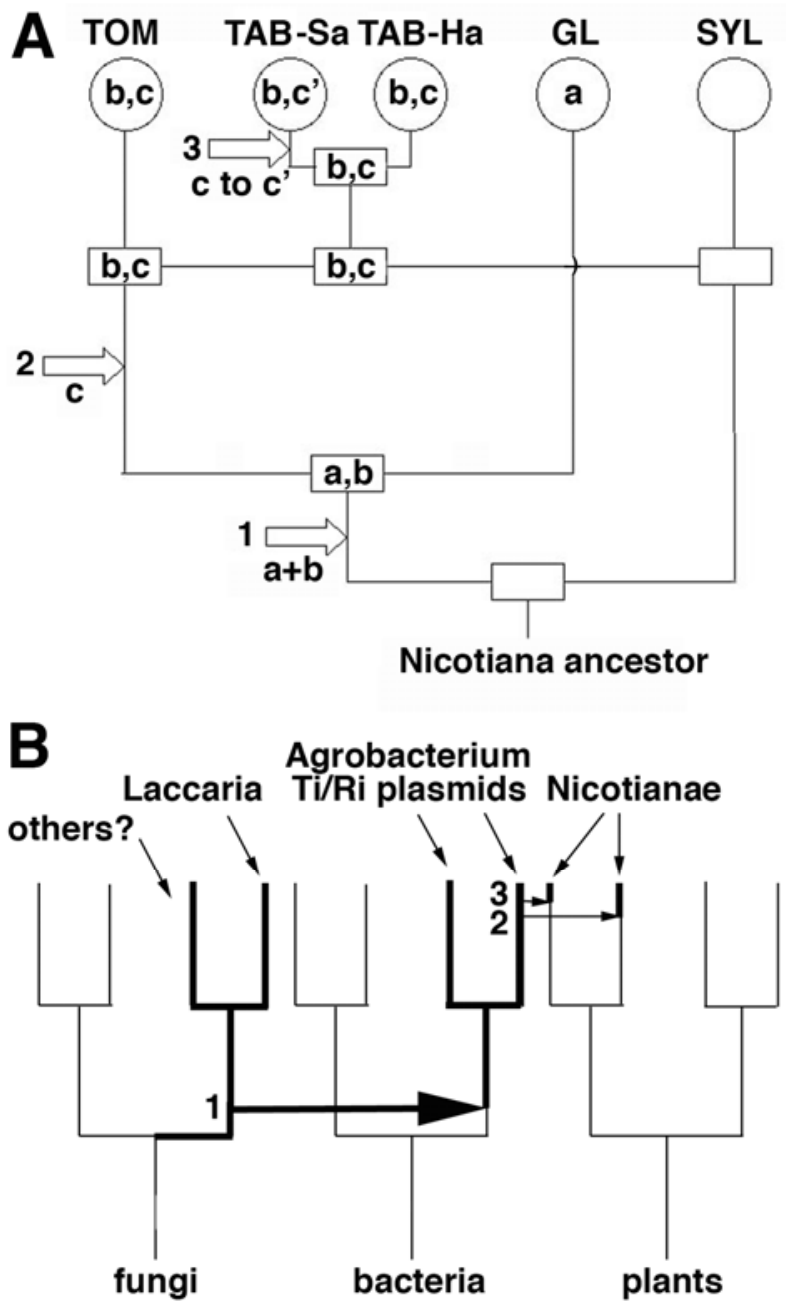

Fig. 10. Evolutionary models. A, Origin of Nicotiana cellular (c)T-DNAs. $\mathrm{TOM}=N$. tomentosiformis, TAB-Sa $=N$. tabacum cv. Samsun, TAB-Ha = $N$. tabacum cv. Havana, GL $=N$. glauca, $\mathrm{SYL}=N$. sylvestris. Circles indicate present-day species, squares ancient species. Arrow 1, Transformation by a 1,724-like mikimopine strain, insertion of an inverted repeat inherited by GL (fragment a) and an orf14-mis fragment inherited by TOM and TAB (fragment b). N. tabacum is a hybrid of N. tomentosiformis and N. sylvestris. Arrow 2, Insertion of a second cT-DNA with orf8-orf13 genes by an unidentified $A$. rhizogenes strain and inherited by TOM and TAB (fragment c). Arrow 3, Partial deletion of torf13 in one group of TAB cultivars, inherited by TAB-Sa and related tobaccos (c to c'). B, Origin of plast genes. Arrow 1, Hypothetical transfer of plast genes from a fungus to Agrobacterium spp. by horizontal gene transfer. Subsequent divergence of plast genes between Agrobacterium spp. and fungi and within Agrobacterium spp. reduced DNA homology to undetectable levels and left only weak protein similarity. Arrows 2 and 3, Recent horizontal transfers of Agrobacterium plast genes to Nicotiana spp., DNA and protein are still significantly homologous. Thick lines indicate species with plast or plastlike genes. to the oriental tobacco group. It would be interesting to test the influence of the wild-type torf13 gene from Havana 425 on cv. Samsun nn and other oriental cultivars, as this may provide some ideas on the consequences of the loss of torf13. We believe our evolutionary model can provide a framework for further studies, especially with regard to cT-DNAs from other Nicotiana species.

$N$. tabacum carries the three essential hairy-root genes rolA, rolB, and rolC, but trolA and trolB are mutated. trolC has strong morphogenetic activity, very similar to that of A4-rolC from $A$. rhizogenes. Functional comparison was facilitated by the use of dex-inducible constructs, avoiding the accumulation of growth abnormalities, as in the case of constitutive genes.

In dex-trolC-HAHIS but not in dex-A4-rolC-HAHIS plants, post-transcriptional gene silencing led to a rapid and strong decrease in transgene mRNA and protein levels, with concomitant reversion to normal phenotypes. The strong trolC-HAHIS silencing merits further investigation, as it might also affect endogenous trolC expression. At the protein level, tRolCHAHIS might compete with putative tRolC partners for binding or other types of interaction, thereby producing dominant negative effects. In addition, it is possible that the various abnormalities induced by strong dex-trolC-HAHIS expression produce indirect changes in expression of the endogenous trolC gene. These possibilities remain to be studied. However, the data from Arabidopsis show that the trolC-HAHIS gene construct does not need to interact with an endogenous trolC gene to produce a strong biological effect.

In this work, we have used several new rolC assays, monitoring growth changes after induction of seedlings, intact plants, leaf disks, or isolated roots. These assays have revealed hitherto unsuspected functional similarities between rolC and $6 b$. In spite of the fact that $6 \mathrm{~B}$ and RolC proteins show only $23 \%$ similarity, $A B-6 b, T-6 b$, trol $C$, and rol $C$ all induce enations. Enations are secondary leaf blades arising in a mirror-wise fashion along the veins of the abaxial leaf side. Since these growth modifications are very unusual, we believe this provides a strong indication that $\mathrm{rol} C$ and $6 b$ impact similar pathways. rolC and $6 b$ also induce leaf chlorosis and starch accumulation. They stimulate leaf-disk expansion on sucrose-containing media, reduce root-hair development and root growth, and stimulate sucrose uptake by root fragments. In view of these results, we propose that the various rolC and $6 b$ effects are caused by enhanced sucrose absorption and retention. RolC is cytosolic (Estruch et al. 1991; Oono et al. 1991) and, therefore, probably not a transporter itself. The regulation of rolC transcription by sucrose and increased hexose levels in rolC transgenic potato has earlier led to the suggestion that rolC plays a role in sucrose metabolism, transport, or both (Nilsson and Olsson 1997). Our studies provide strong experimental support for this idea and indicate a role in sucrose uptake. In natural A. rhizogenes infections, sucrose accumulation may stimulate initiation and outgrowth of hairy roots. Since the tobacco trolC gene is expressed (Meyer et al. 1995) and functionally active in tobacco (this study), it could play a significant role in tobacco growth and physiology.

In spite of their similarities, $6 b$ and rol $C$ plants also show characteristic differences. $6 b$ plants have dramatically expanded roots and show ectopic divisions in the root stele, around leaf veins, and on seedling stems (Grémillon et al. 2004; Helfer et al. 2003); contrary to this, trolC or A4-rolC plants do not. Instead, trolC and $A 4$-rolC leaves are pale green and narrow, show wrinkled edges and irregular chlorosis, and are epinastic in seedlings. Possibly, these differences are due to differences in plast protein mobility. The $6 b$ phenotype is graft-transmissible (Helfer et al. 2003) and the 6B protein moves in leaves (Grémillon et al. 2004), whereas rolC effects are cell autonomous (Fladung 
and Ahuja 1997; Fladung et al. 2004; Gidoni et al. 2001; Spena et al. 1989). 6B has also been shown to interact with the NtSIP1 protein (Kitakura et al. 2002) and to enter the nucleus (in which it acts as a histone $\mathrm{H} 3$ chaperone protein; Terakura et al. 2007). In view of the partial functional similarities between the RolC/tRolC and $6 \mathrm{~B}$ proteins, it will be interesting to test the interaction of RolC/tRolC with NtSIP1 and H3 and their possible localization in the nucleus. Whether other plast genes share activities with rolC and $6 b$ remains to be tested. Interestingly, the rolB-like $5^{\prime}$ part of orf 8 expressed under $2 \times 35 \mathrm{~S}$ promoter control causes dwarfing, irregular leaf chlorosis, and starch accumulation in tobacco with a strong reduction of sucrose export (Otten and Helfer 2001; Umber et al. 2002).

Our studies confirm that rolC accelerates flowering as noted in tobacco and in other plant species (Casanova et al. 2005; Faiss et al. 1996). Possibly, this rolC property led to rapid speciation of the initial Nicotiana transformants.

The occurrence of plast-like genes in the ectomycorrhizal basidiomycete Laccaria bicolor is of considerable interest. The close association of Agrobacterium spp. and Laccaria spp. with plant roots and their common interest in plant-derived metabolites (López et al. 2008) might have favored horizontal DNA transfer from the fungus to the bacterium (Fig. 10B, arrow 1a). A long period of divergence then generated the many different Agrobacterium plast genes. Although a transfer from the bacterium to the fungus cannot be excluded, the lack of other T-DNA genes, like opine synthesis genes (often found close to the right T-DNA borders and, therefore, likely to be cotransferred) and hormone synthesis genes in the two chromosomal Laccaria regions that contain plast-like genes, makes this less likely. More recently, at least two transfers occurred from Agrobacterium spp. to Nicotiana spp. (Fig. 10B, arrow 2 and 3). The distribution of plast-like genes in other fungi, their role in Laccaria spp. and their effects on plants should constitute topics for further studies.

\section{MATERIALS AND METHODS}

\section{A4-rolC and trolC constructs.}

For constitutive expression, A4-rolC and trolC coding regions were cloned in a $2 \times 35 \mathrm{~S}$ promoter cassette by PCR and were subcloned into the pBI121.2 binary vector (Jefferson et al. 1987) as described for other constructs (Otten and Helfer 2001). Dex-inducible constructs were prepared as for dex-T-6b (Grémillon et al. 2004), using the pTA7002 binary vector (Aoyama and Chua 1997). At the locations indicated, a HAHIS tag from pNTL2104 (Thomas et al. 2006) was added at the 3' end, to permit protein detection using antihemagglutinin antibodies. All constructs were checked by sequencing before subcloning. Binary vectors with constructs were introduced in the disarmed Agrobacterium helper strain LBA4404 (Hoekema et al. 1983).

\section{Transformation and regeneration.}

Tobacco transformation and regeneration was as described (Otten and Helfer 2001). Arabidopsis thaliana ecotype Colombia (Col-0) plants were transformed by the floral dip method (Clough and Bent 1998).

\section{Induction by dex.}

Plants were induced with dex in different ways. Mature leaves were infiltrated with a dex solution in $10 \mathrm{mM} \mathrm{MgSO}_{4}$, using a 1-ml syringe without a needle. Seedlings were germinated on MS255 (Duchefa, Haarlem, The Netherlands) agar plates with $1 \%$ sucrose and, 10 days later, were placed on nylon filters on vertical plates with the same medium and, 3 days after that, were transferred to inducing vertical plates. Leaf disks were induced by floating them upside down on a solution of $10 \mathrm{mM} \mathrm{KCl}, 0.5 \mathrm{mM}$ HEPES buffer, $\mathrm{pH}$ 6.0, with varying concentrations of sucrose and were weighed at 1-day intervals (Clément et al. 2006; Keller and Van Volkenburgh 1997). Intact small or medium-sized plants in soil were sprayed on 2 consecutive days with $3 \mu \mathrm{M}$ dex and $0.05 \%$ Tween-20 in water. Leaves of different sizes were locally induced by placing lanolin spheres ( $1 \mathrm{~mm}$ in diameter) containing $10 \mu \mathrm{M}$ dex on the upper leaf surface. One week later, disks were removed and stained for starch with iodine.

\section{Sucrose absorption.}

Sucrose absorption was tested with 3-mm-long root fragments situated originally at 9 to $12 \mathrm{~mm}$ from the root apex. These fragments were obtained from intact seedlings grown for 3 days on inducing medium on vertical plates. Five fragments were floated on a $15-\mu 1$ drop of MS255 medium with 1 $\mathrm{mM}{ }^{14} \mathrm{C}$-sucrose in microtiter plates (Clément et al. 2007). Radioactivity in the medium was measured at the start of the experiment and after $24 \mathrm{~h}$; all experiments were carried out in triplicate.

\section{Arabidopsis thaliana seed germination.}

Arabidopsis thaliana seeds (generation T3) were germinated on MS255 medium in the presence of $50 \mathrm{mg}$ of kanamycin per liter and $1 \%$ sucrose for 8 days and were then transferred to soil or to nylon filters on vertical agar plates containing the same medium.

\section{RNA extraction and siRNA gel blotting.}

RNA was extracted from leaves of tobacco seedlings using Tri-Reagent (Sigma, St. Louis). Leaves of 15 plants (two leaves per plant) were ground in liquid nitrogen. The resulting powder was homogenized in $1 \mathrm{ml}$ of Trizol and $200 \mu \mathrm{l}$ of chloroform was added. The upper phase was precipitated with 1 volume of isopropanol. After washing with $70 \%$ ethanol (1 $\mathrm{ml}$ ), RNAs were taken up in RNAse-free $\mathrm{H}_{2} \mathrm{O}$. RNA gel-blot analysis of low-molecular-weight RNA was conducted on 25 $\mu \mathrm{g}$ of total RNA as described (Akbergenov et al. 2006). The $A 4$-rolC coding sequence and the 183 to 395 fragment of the trolC coding sequence were used as probes. Blots were stripped and were rehybridized with a probe complementary to U6 RNA as a loading control (Gy et al. 2007).

\section{RNA extraction and RT-quantitative PCR.}

RNA was extracted as described above. After being treated with RNase-free DNase kit (Qiagen, Hilden, Germany), cDNA was synthesized with $5 \mu \mathrm{g}$ of total RNA, using the Superscript III reverse transcription kit (Invitrogen, Carlsbad, CA, U.S.A.). Real-time qPCR reactions $(10 \mu \mathrm{l})$ were performed in 384-well optical plates on a BioRad i-cycler apparatus using PCR master 2× mix (Roche Molecular Systems, Branchburg, NJ, U.S.A.) containing 480 SYBER Green I fluorescein reporter with gene-specific primers. Quantification was performed in triplicate. Nicotiana tabacum translation elongation factor gene (EF2; GenBank accession number AJ299248.1) was used as an internal standard for equalization of RNA levels. Quantifications were then normalized to noninduced tobacco plantlets. Experiments were repeated three times in a biologically independent manner.

\section{RT-qPCR primers.}

Primers used for RT-qPCR are as follows: EF2-Forward, 5'ctgaaccagaagcgtggaca-3'; EF2-Reverse, 5'-ccagatgtagcagccctc aag-3'; trolC-Forward, 5'-ctgaaccagaagcgtggaca-3'; trolC-Reverse, 5'-ccctgacattcagtctttatgcac-3'; rolC-Forward, 5'-gggcagt cgacgtagagg-3'; rolC-Reverse, 5'-cgatggatattgacgaagaagg-3'. 


\section{Sequencing primers.}

The sequencing primers for the torf8-torf 13 fragment were: D1958， 5'-gaatcggcacgaggcaaccattattt-3' (from EH664027); D1686, 5'-tgcagagatttatcgggctca-3' (primer 10 in Meyer and associates [1995]); D1734, same as D1686 but reverse complement; D1884, 5'-cccgaacaggagttatgga-3' (from AF281242.1). The sequencing primers for the torfl4-tmis fragment were: D1917, 5'-tgagcatgccgtcttgac-3' (from AB071334.1); D1865, $5^{\prime}$-cccttttcgttaataagatggacctt- $3^{\prime}$ (from AB071334.1).

General PCR conditions were: $5 \mathrm{~min}$ at $94^{\circ} \mathrm{C}$, and then, 30 cycles at $94^{\circ} \mathrm{C}(20 \mathrm{~s}), 60^{\circ} \mathrm{C}(20 \mathrm{~s})$, and $72^{\circ} \mathrm{C}(30 \mathrm{~s})$, followed by $10 \mathrm{~min}$ at $72^{\circ} \mathrm{C}$. Conditions were adapted with respect to primer sequence and expected fragment length.

\section{ACKNOWLEDGMENTS}

We thank F. Dorlhac at the Institut du Tabac at Bergerac, France for seeds of different tobacco cultivars. We thank the gardeners of the Institut de Biologie Moléculaire des Plantes (Strasbourg, France) for providing plants. H. Mohajjel-Shoja was supported by a doctoral grant from the French Ministry of Research and higher education. This research was financed by the French organization for scientific research Centre National de la Recherche Scientifique (Paris).

\section{LITERATURE CITED}

Akbergenov, R., Si-Ammour, A., Blevins, T., Amin, I., Kutter, C., Vanderschuren, H., Zhang, P., Gruissem, W., Meins, F., Jr,. Hohn, T. and Pooggin, M. 2006. Molecular characterization of geminivirusderived small RNAs in different plant species. Nucleic Acids Res. 34:462-471.

Aoki S. 2004. Resurrection of an ancestral gene: Functional and evolutionary analyses of the $\mathrm{Ngrol}$ genes transferred from Agrobacterium to Nicotiana. J. Plant Res. 117:329-37.

Aoki, S., and Syono, K. 1999a. Horizontal gene transfer and mutation: ngrol genes in the genome of Nicotiana glauca. Proc. Natl. Acad. Sci. U.S.A. 96:13229-34.

Aoki, S., and Syono, K. 1999b. Synergistic function of rolB, rolC, ORF13 and ORF14 of TL-DNA of Agrobacterium rhizogenes in hairy root induction in Nicotiana tabacum. Plant Cell Physiol. 40:252-256.

Aoki, S., and Syono, K. 1999c. Function of $\mathrm{Ngrol}$ genes in the evolution of Nicotiana glauca: Conservation of the function of $\mathrm{NgORF} 13$ and $\mathrm{NgORF14}$ after ancient infection by an Agrobacterium rhizogenes-like ancestor. Plant Cell. Physiol. 40:222-230.

Aoki, S., Kawaoka, A., Sekine, M., Ichikawa, T., Fujita, T., Shinmyo, A., and Syono, K. 1994. Sequence of the cellular T-DNA in the untransformed genome of Nicotiana glauca that is homologous to ORFs 13 and 14 of the Ri plasmid and analysis of its expression in genetic tumours of N. glauca x N. langsdorffii. Mol. Gen. Genet. 243:706-10.

Aoyama, T., and Chua, N-H. 1997. A glucocorticoid-mediated transcriptional induction system in transgenic plants. Plant J. 11:605-612.

Capone, I., Spano, L., Cardarelli, M., Bellincampi, D., Petit, A., and Costantino, P. 1989. Induction and growth properties of carrot roots with different complements of Agrobacterium rhizogenes T-DNA. Plant Mol. Biol. 13:43-52.

Casanova, E., Trillas, M.I., Moysset, L., and Vainstein, A. 2005. Influence of $r o l$ genes in floriculture. Biotechnol. Adv. 23:3-39.

Clément, B., Pollmann, S., Weiler, E., Urbanczyk-Wochniak, E., and Otten, L. 2006. The Agrobacterium vitis T-6b oncoprotein induces auxin-independent cell expansion in tobacco. Plant J. 45:1017-27.

Clément, B., Perot, J., Geoffroy, P., Legrand, M., Zon, J., and Otten, L. 2007. Abnormal accumulation of sugars and phenolics in tobacco roots expressing the Agrobacterium T- $6 b$ oncogene and the role of these compounds in $6 b$-induced growth. Mol. Plant-Microbe Interact. 20:53-62.

Clough, S. J., and Bent, A. F. 1998. Floral dip: A simplified method for Agrobacterium-mediated transformation of Arabidopsis thaliana. Plant J. 16:735-43.

Costantino, P., Capone, I., Cardarelli, M., De Paolis, A., Mauro, M. L., and Trovato, M. 1994. Bacterial plant oncogenes: The rol genes' saga. Genetica 94:203-11

Estruch, J. J., Parets-Soler, A., Schmülling, T., and Spena, A. 1991. Cytosolic localization in transgenic plants of the rolC peptide from Agrobacterium rhizogenes. Plant Mol Biol. 17:547-50.

Faiss, M., Strnad, M., Redig, P., Dolezal, K., Hanus, J., van Onckelen, H., and Schmülling, T. 1996. Chemically induced expression of the rolCencoded $\beta$-glucosidase in transgenic tobacco plants and analysis of cy- tokinin metabolism: rolC does not hydrolyze endogenous cytokinin glucosides in planta. Plant J. 10:33-46.

Fladung, M., and Ahuja, M. R. 1997. Excision of the maize transposable element Ac in periclinal chimeric leaves of 35S-Ac-rolC transgenic aspen-Populus. Plant Mol. Biol. 33:1097-103.

Fladung, M., Deutsch, F., Hönicka, H., and Kumar, S. 2004. T-DNA and transposon tagging in aspen. Plant Biol. 6:5-11.

Fründt, C., Meyer, A. D., Ichikawa, T., and Meins, F. 1998. A tobacco homologue of the Ri-plasmid orf13 gene causes cell proliferation in carrot root disks. Mol. Gen. Genet. 259:559-68.

Furner, I. J., Huffman, G. A., Amasino, R. M., Garfinkel, D. J., Gordon, M. P., and Nester, E. W. 1986. An Agrobacterium transformation in the evolution of the genus Nicotiana. Nature 319:422-427.

Gidoni, D., Bar, M., and Gilboa, N. 2001. FLP/FRT-mediated restoration of normal phenotypes and clonal sectors formation in rolC transgenic tobacco. Transgenic Res. 10:317-328.

Grémillon, L., Helfer, A., Clément, B., and Otten, L. 2004. New plant growth-modifying properties of the Agrobacterium T- $6 b$ oncogene revealed by the use of a dexamethasone-inducible promoter. Plant $\mathrm{J}$. 37:218-228.

Gy, I., Gasciolli, V., Lauressergues, D., Morel, J.B., Gombert, J., Proux, F., Proux, C., Vaucheret, H., and Mallory, A. C. 2007. Arabidopsis FIERY1, XRN2, and XRN3 are endogenous RNA silencing suppressors. Plant Cell 19:3451-61.

Hansen, G., Larribe, M., Vaubert, D., Tempé, J., Biermann, B. J., Montoya, A. L., Chilton, M-D., and Brevet, J. 1991. Agrobacterium rhizogenes pRi8196 T-DNA: Mapping and DNA sequencing of functions involved in mannopine synthesis and hairy root differentiation. Proc. Natl. Acad. Sc. U.S.A. 88:7763-7767.

Helfer, A., Pien, S., and Otten, L. 2002. Functional diversity and mutational analysis of Agrobacterium 6B oncoproteins. Mol. Gen. Genomics 267:577-586.

Helfer, A., Clément, B., Michler, P., and Otten, L. 2003. The Agrobacterium oncogene $\mathrm{AB}-6 b$ causes a graft-transmissible enation syndrome on tobacco. Plant Mol. Biol. 52:483-493.

Hoekema, A., Hirsch, P. R., Hooykaas, P. J. J., and Schilperoort, R. A. 1983. A binary vector system based on separation of vir- and T-region of the Agrobacterium Ti plasmid. Nature 303:179-180.

Intrieri, M. C., and Buiatti, M. 2001. The horizontal transfer of Agrobacterium rhizogenes genes and the evolution of the genus Nicotiana. Mol. Phylogenet. Evol. 20:100-10.

Jefferson, R. A., Kavanagh, T. A., and Bevan, M. 1987. GUS fusions: $\beta$ glucuronidase as a sensitive and versatile gene fusion marker in higher plants. EMBO (Eur. Mol. Biol. Organ.) J. 6:3901-3907.

Keller, C. P., and Van Volkenburgh, E. 1997. Auxin-induced epinasty of tobacco leaf tissues. A non-ethylene mediated response. Plant Physiol. 113:603-610

Kelly, L. J., Leitch, A. R., Clarkson, J. J., Hunter, R. B., Knapp, S., and Chase, M. 2010. Intragenic recombination events and evidence for hybrid speciation in Nicotiana (Solanaceae). Mol. Biol. Evol. 27:781-799.

Kitakura, S., Fujita, T., Ueno, Y., Terakura, S., Wabiko, H., and Machida, Y. 2002. The protein encoded by the oncogene $6 b$ from Agrobacterium tumefaciens interacts with a nuclear protein of tobacco. Plant Cell 14:451-463.

Lemcke, K., and Schmülling, T. 1998. Gain of function assays identify non-rol genes from Agrobacterium rhizogenes TL-DNA that alter plant morphogenesis or hormone sensitivity. Plant J. 15:423-433.

Levesque, H., Delepelaire, P., Rouzé, P., Slightom, J., and Tepfer, D. 1988. Common evolutionary origin of the central portion of the Ri TL-DNA of Agrobacterium rhizogenes and the Ti T-DNAs of Agrobacterium tumefaciens. Plant Mol. Biol. 11:731-744.

López, M. F., Dietz, S., Grunze, N., Bloschies, J., Weiss, M., and Nehls, U. 2008. The sugar porter gene family of Laccaria bicolor: Function in ectomycorrhizal symbiosis and soil-growing hyphae. New Phytol. 180:365-78.

Martin, F., and others, 2008. The genome of Laccaria bicolor provides insight into the mycorrhizal symbiosis. Nature 452:88-92.

Meyer, A. D., Ichikawa, T., and Meins, F. 1995. Horizontal gene transfer: Regulated expression of a tobacco homologue of the Agrobacterium rhizogenes rolC gene. Mol. Gen. Genet. 249:265-73.

Meyer, A., Tempé, J., and Costantino, P. 2000. Hairy root: A molecular overview. Functional analysis of Agrobacterium rhizogenes T-DNA genes. Pages 93-139 in: Plant-Microbe Interactions, Vol. 5. G. Stacey and N. T. Keen, eds. American Phytopathological Society Press, St. Paul, MN, U.S.A.

Nagata, N., Kosono, S., Sekine, M., Shinmyo, A., and Syono, K. 1995. The regulatory functions of the rolB and rolC genes of Agrobacterium rhizogenes are conserved in the homologous genes (Ngrol) of Nicotiana glauca in tobacco genetic tumors. Plant Cell Physiol. 36:1003-12.

Nilsson, O., and Olsson, O. 1997. Getting to the root: The role of the 
Agrobacterium rhizogenes rol genes in the formation of hairy roots. Physiol. Plant. 100:463-473.

Nilsson, O., Moritz, T., Imbault, N., Sandberg, G., and Olsson, O. 1993. Hormonal characterization of transgenic tobacco plants expressing the rolC gene of Agrobacterium rhizogenes TL-DNA. Plant Physiol. 102:363-371.

Oono, Y., Satomi, T., and Uchimiya, H. 1991. Agrobacterium rhizogenes lacZ-rolC gene expression in Escherichia coli: Detection of the product in transgenic plants using RolC-specific antibodies. Gene 104:95-8.

Otten, L., and Helfer, A. 2001. Biological activity of the rolB-like $5^{\prime}$ end of the A4-orf8 gene from the Agrobacterium rhizogenes TL-DNA. Mol. Plant-Microbe Interact. 14:405-411.

Schmülling, T., Schell, J., and Spena, A. 1988. Single genes from Agrobacterium rhizogenes influence plant development. EMBO (Eur. Mol. Biol. Organ.) J. 7:2621-2629.

Shen, W. H. 2001. NtSET1, a member of a newly identified subgroup of plant SET-domain-containing proteins, is chromatin-associated and its ectopic overexpression inhibits tobacco plant growth. Plant J. 28:371-383.

Spena, A., Schmülling, T., Koncz, C., and Schell, J. S. 1987. Independent and synergistic activity of $\operatorname{rol} A, B$ and $C$ loci in stimulating abnormal growth in plants. EMBO (Eur. Mol. Biol. Organ.) J. 6:3891-3899.

Spena, A., Aalen, R. B., and Schulze, S. C. 1989. Cell-autonomous behav- ior of the rolC gene of Agrobacterium rhizogenes during leaf development: A visual assay for transposon excision in transgenic plants. Plant Cell 1:1157-64.

Studholme, D. J., Downie, J. A., and Preston, G. M. 2005. Protein domains and architectural innovation in plant-associated Proteobacteria. BMC Genomics 6:1-25.

Suzuki, K., Yamashita, I., and Tanaka, N. 2002. Tobacco plants were transformed by Agrobacterium rhizogenes infection during their evolution. Plant J. 32:775-87.

Terakura, S., Ueno, Y., Tagami, H., Kitakura, S., Machida, C., Wabiko, H., Aiba, H., Otten, L., Tsukagoshi, H., Nakamura, K., and Machida, Y. 2007. An oncoprotein from the plant pathogen Agrobacterium has histone chaperone-like activity. Plant Cell 19:2855-2865.

Thomas, C., Hoffmann, C., Dieterle, M., Van Troys, M., Ampe, C., and Steinmetz, A. 2006. Tobacco WLIM1 is a novel F-actin binding protein involved in actin cytoskeleton remodeling. Plant Cell 18:2194-2206.

Umber, M., Voll, L., Weber, A., Michler, P., and Otten, L. 2002. The rolBlike part of the Agrobacterium rhizogenes orf8 gene inhibits sucrose export in tobacco. Mol. Plant-Microbe Interact. 15:956-62.

White, F., Garfinkel, D., Huffman, G. A., Gordon, M., and Nester, E. W. 1983. Sequences homologous to Agrobacterium rhizogenes T-DNA in the genomes of uninfected plants. Nature 301:348-350. 